\title{
Utilização da Paisagem para o Planejamento de um Circuito de Ecoturismo na Reserva Volta Velha - Itapoá - Santa Catarina
}

\author{
Landscape use for the Planning of an Ecotourism Circuit at the Reserva Volta \\ Velha - Itapoá - Santa Catarina
}

\author{
Celso Darci Seger ${ }^{1}$ \\ Daniela Biondi ${ }^{2}$
}

\begin{abstract}
Resumo
Dentre os segmentos turísticos praticados em contato direto com a natureza, o ecoturismo se destaca por ser considerado de baixo impacto, gerador de conhecimentos e conscientização ambiental. Apesar desses aspectos positivos, a falta de planejamento que vise ordenar as atividades e minimizar os impactos negativos que possam ser provocados na paisagem, faz com que esse segmento seja desenvolvido muitas vezes de forma desvirtuada de seu real conceito. O presente estudo teve como proposta o planejamento de um circuito de ecoturismo na Reserva Volta Velha - Itapoá - Santa Catarina, utilizando-se a paisagem como recurso técnico. O resultado obtido foi o planejamento de um circuito de ecoturismo com interferências de baixa magnitude nos sítios ambientais e histórico-culturais presentes na reserva.
\end{abstract}

Palavras-chave: planejamento turístico; paisagem; reserva Volta Velha; Itapoá; Santa Catarina.

\begin{abstract}
Among the tourist segments which involve direct contact with nature, ecotourism stands out for having low impact, generating knowledge, and bringing environmental awareness as well. Yet in spite of these positive aspects, the lack of planning in the sense of coordinating activities and minimizing the negative impacts which may arise at the landscape, causes its chore concept to lose the original appeal. This study seeks to plan an ecotourism circuit at Reserva Volta Velha - Itapoá - Santa Catarina, utilizing the landscape as a planning resource. The result of the study was a planning an ecotourism circuit with low-magnitude interferences in the environmental and historic/cultural sites found in the reserve.
\end{abstract}

Keywords: tourism planning; landscape; Volta Velha reserv; Itapoá; Santa Catarina.

\footnotetext{
${ }^{1}$ Biólogo M. Sc. E-mail: celsoseger@terra.com.br

${ }^{2}$ Eng. Florestal. Prof ${ }^{a}$. Dr ${ }^{a}$ Depto. de Ciências Florestais - UFPR. E-mail: dbiondi@ufpr.br
} 


\section{Introdução}

O ecoturismo é definido pela EMBRATUR (2005) como sendo o segmento turístico que utiliza o patrimônio natural e cultural de forma sustentável, incentiva a sua conservação e busca a formação de uma consciência ambientalista por meio da interpretação do ambiente, promovendo o bem-estar das populações envolvidas.

Esse segmento, considerado por Wearing e Neil (2001) como uma extensão ou apêndice do turismo alternativo, vem apresentado um crescimento em diferentes países, principalmente pela insatisfação das pessoas com as formas convencionais de turismo (Fennel, 2002). Além de uma alternativa econômica para regiões que ainda mantém características ambientais primitivas, o ecoturismo tem em seu contexto a educação conservacionista, importante para a sensibilização das pessoas e formação de uma consciência ambiental.

Dentre os espaços potenciais para a prática do ecoturismo, as Unidades de Conservação abertas à visitação pública tem destaque, em especial as categorias Parque (Nacionais, Estaduais e Municipais) e as Reservas Particulares do Patrimônio Natural - RPPNs (Milano, 1993). Para as RPPNs, o ecoturismo representa uma das poucas alternativas de geração de renda que pode contribuir com a sua manutenção, pois, segundo o decreto que estabelece a criação dessa categoria de manejo (MMA, 2000), a mesma fica instituída em caráter de perpetuidade como de proteção ambiental integral. Por esse motivo, muitos proprietários têm interesse em implantar programas de ecoturismo em suas reservas, principalmente pelo fato dessas áreas apresentarem na maioria das vezes cenários apropriados para o desenvolvimento desse segmento turístico. Se por um lado é interessante no aspecto do retorno financeiro para compensar o ato da conservação, por outro, gera preocupações, pois, de acordo com Pires (1993) o ecoturismo, assim como outros segmentos turísticos também pode ser gerador de impactos negativos significativos se as atividades não forem realizadas de forma criteriosa e consciente. Dessa forma, o referido autor salienta da importância para que toda a atividade de ecoturismo seja planejada e realizada dentro de uma lógica que propicie a utilização do espaço natural com a conservação dos recursos nelas existentes.

Sobre a mesma questão, Costa (2002) afirma que a falta de planejamento da atividade ecoturistica pode gerar degradação de áreas que contenham recursos naturais de relevância para conservação. Portanto, ao mesmo tempo em que se apresenta como uma atividade econômica desenvolvida em consonância com a conservação ambiental pode ter um efeito contrário ao pretendido se não for bem planejada. 
Com base no exposto pelos autores citados e a preocupação de se fazer o uso manejado e sustentável do espaço natural da Reserva Volta Velha no município de Itapoá-SC, a pesquisa desenvolvida teve como proposta o planejamento das atividades de ecoturismo na referida reserva. Essa unidade de conservação particular por apresentar em seus limites uma diversidade de ambientes é uma área potencial para a prática do ecoturismo, mas, ao mesmo tempo, também suscetível à degradação em face à fragilidade de alguns dos elementos que compõe o meio biótico e o meio abiótico ali presentes. A falta de um planejamento das atividades com base em estudo técnico poderia gerar impactos de diferentes magnitudes e possivelmente desvirtuar o verdadeiro propósito de criação da reserva.

Para a elaboração do planejamento utilizou-se a paisagem como recurso, considerando que a paisagem dentro de um contexto técnico constitui-se da interação dos componentes bióticos e abióticos de uma determinada área, sendo que cada componente pode sofrer maior ou menor depreciação por meio das ações antrópicas influenciadas por condicionantes ligadas à localização, declividade e clima, dentre outras.

A paisagem como recurso técnico, é considerada por muitos autores como um instrumento bastante útil de planejamento de atividades turísticas (incluindo o ecoturismo). Utilizada há décadas em países mais desenvolvidos para a análise, avaliação e gestão de territórios, é atualmente empregada em ciências como a ecologia, a geografia, a biologia e a sociologia, em estudos que englobam tanto os aspectos naturais como os culturais (Boullón, 2002). No Brasil, seu uso ainda é incipiente, provavelmente devido ao fato dos planejadores do nosso país não levarem em conta o potencial da mesma para estudos direcionados ao uso do solo para atividades distintas (Bolson, 2004), além do que, ainda não existirem técnicas ou procedimentos padronizados para a realização dos referidos estudos (Griffith, 1979).

Em atividades realizadas em contato com ambientes naturais como é o caso do ecoturismo, Wagar $^{3}$ citado por Griffith (1979) considera o inventário paisagístico uma importante ferramenta para a avaliação e proposição de traçados a serem utilizados. Cita ainda que a paisagem nesse caso deva ser compreendida, analisada e, sobretudo, ter suas modificações controladas e limitadas para que essa atividade seja realizada de uma forma harmoniosa com os recursos ambientais e sócio-culturais de uma determinada região.

O objetivo geral do presente trabalho foi à análise da paisagem para o planejamento de um circuito de ecoturismo na Reserva Volta Velha em Itapoá-SC.

\footnotetext{
${ }^{3}$ WAGAR, J. A. Recreation and aesthetic conditions. General Technical Report, PNW - 24, Portland, Ore., 1974. $15 \mathrm{p}$.
} 
Os objetivos específicos foram: avaliar os recursos naturais e paisagísticos presentes na área de estudo; determinar uma área potencial para a prática do ecoturismo na reserva, de acordo com as paisagens presentes; indicar os sítios para a implantação das trilhas a serem utilizadas no programa de ecoturismo da reserva; avaliar os impactos provocados aos elementos naturais e sugerir medidas de minimização; avaliar a fragilidade e capacidade de absorção visual da paisagem ao longo das trilhas onde ocorreram maiores alterações ambientais para a sua implantação; propor atividades voltadas à interpretação da natureza, contemplação de paisagens, resgate histórico-cultural da reserva e ao entretenimento.

\section{Localização e Caracterização da Área de Estudo}

A Reserva Volta Velha está situada na porção central do município de Itapoá - SC (Figura 1), sob as coordenadas geográficas médias de latitude $26^{\circ} 04^{\prime} 56^{\prime \prime} \mathrm{S}$ e longitude $48^{\circ} 38^{\prime} 26^{\prime \prime} \mathrm{W}$ de Greenwich (Negrelle, 1995). É composta por duas propriedades (Fazendas Palmital e Santa Clara) com uma área total de 1.180 hectares, sendo desses, em torno de 1100 hectares recobertos de Floresta Ombrófila Densa de Terras Baixas (IBGE, 1992).

A Fazenda Palmital com 586 hectares é destinada à conservação integral através de criação de uma Reserva Particular do Patrimônio Natural (RPPN Palmital) instituída em caráter de perpetuidade de acordo com a portaria 070/92-N de 25 de junho de 1992, do IBAMA Superintendência Santa Catarina. Até o momento, é a única unidade de conservação existente no município de Itapoá e uma das poucas na região do Litoral Norte Catarinense que mantém uma parcela dos recursos naturais de ecossistemas costeiros de planície litorânea quaternária do Sul do Brasil. A Fazenda Santa Clara com 594 hectares apresenta aproximadamente 90\% de sua área coberta por florestas em diferentes estágios de sucessão. Os 10\% restantes são de área aberta (campos antrópicos) onde se encontra a sede administrativa da reserva, o centro de recepção de visitantes e alojamentos para acomodação de turistas e estudantes, além de monocultura de palmeira-real (Archantophenix sp) para produção de palmito.

Um aspecto marcante da reserva são os vários estudos com a flora, a fauna e a geologia realizados durante anos por profissionais ligados a instituições de ensino e pesquisa. Esses estudos resultaram num dos mais completos bancos de dados de uma unidade de conservação particular no território de Santa Catarina, tornando a mesma conhecida não apenas no contexto nacional, mas também internacional. Devido a esse particular, é considerada como uma área piloto para conservação de ecossistemas dentro da Reserva da Biosfera da Mata Atlântica. 

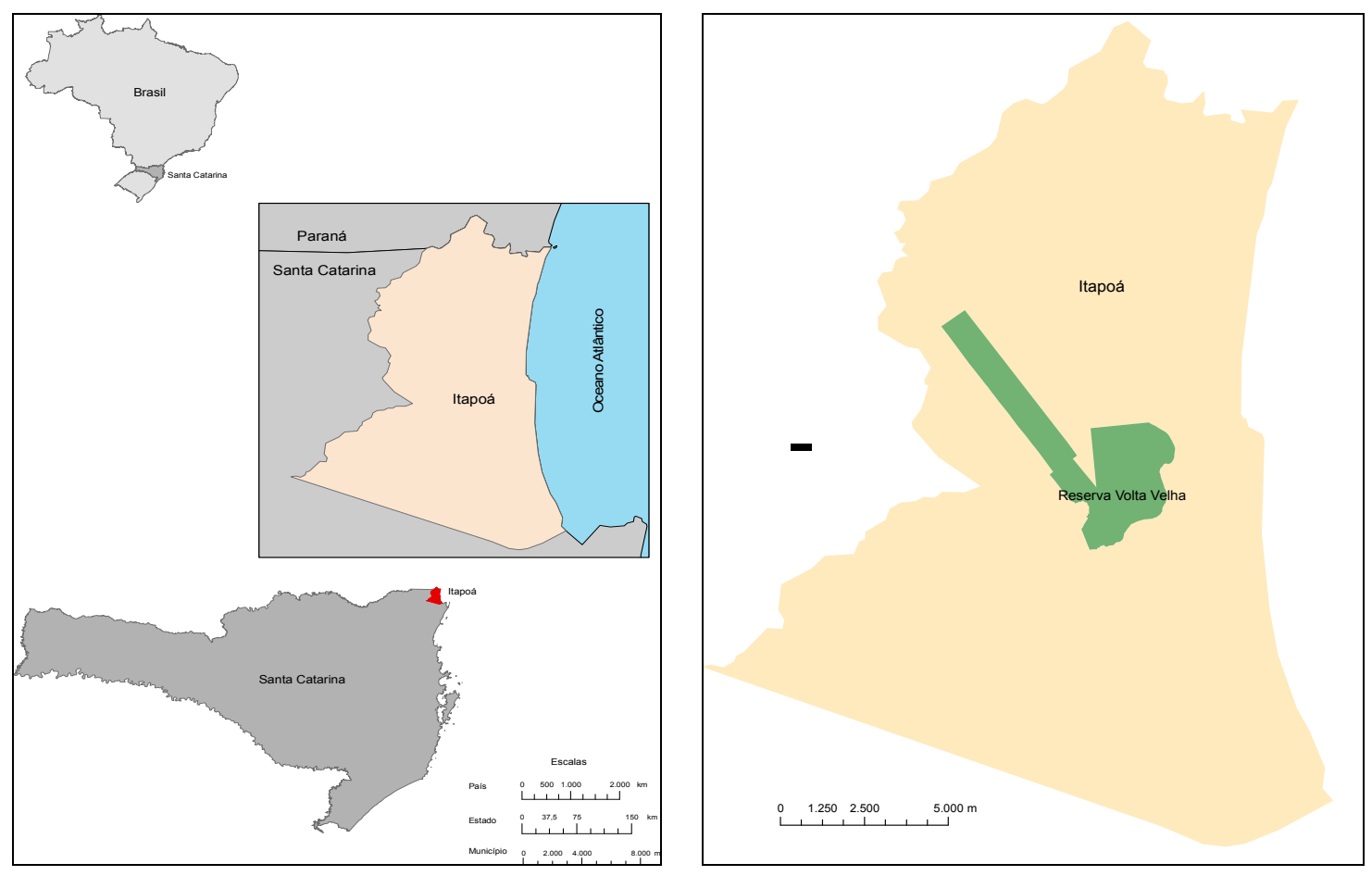

Figura 1 - Localização do município de Itapoá no Estado de Santa Catarina e da Reserva Volta Velha no município.

\section{Procedimentos Metodológicos}

Os procedimentos metodológicos empregados para a obtenção de dados e geração dos resultados resumem-se na realização de diferentes etapas de trabalho conforme fluxograma apresentado na figura 2 e descrição a seguir.

a) Levantamento de dados: constou de um levantamento de dados por meio de revisão bibliográfica de todos os trabalhos de pesquisa realizados na área da reserva e de atividades de campo. Com a compilação desses dados montou-se uma base de dados que contribuíram para o planejamento do circuito de ecoturismo da Reserva Volta Velha.

b) Escolha de área para a implantação do circuito de ecoturismo: a escolha da área para a implantação do circuito de ecoturismo na reserva teve como critérios os seguintes: presença de maior diversidade paisagística; facilidade de acesso e deslocamento; possibilidade de realização de diferentes atividades ligadas ao ecoturismo; estruturação do circuito com baixo investimento; geração de impactos negativos a ambientes e paisagens de baixa magnitude. 


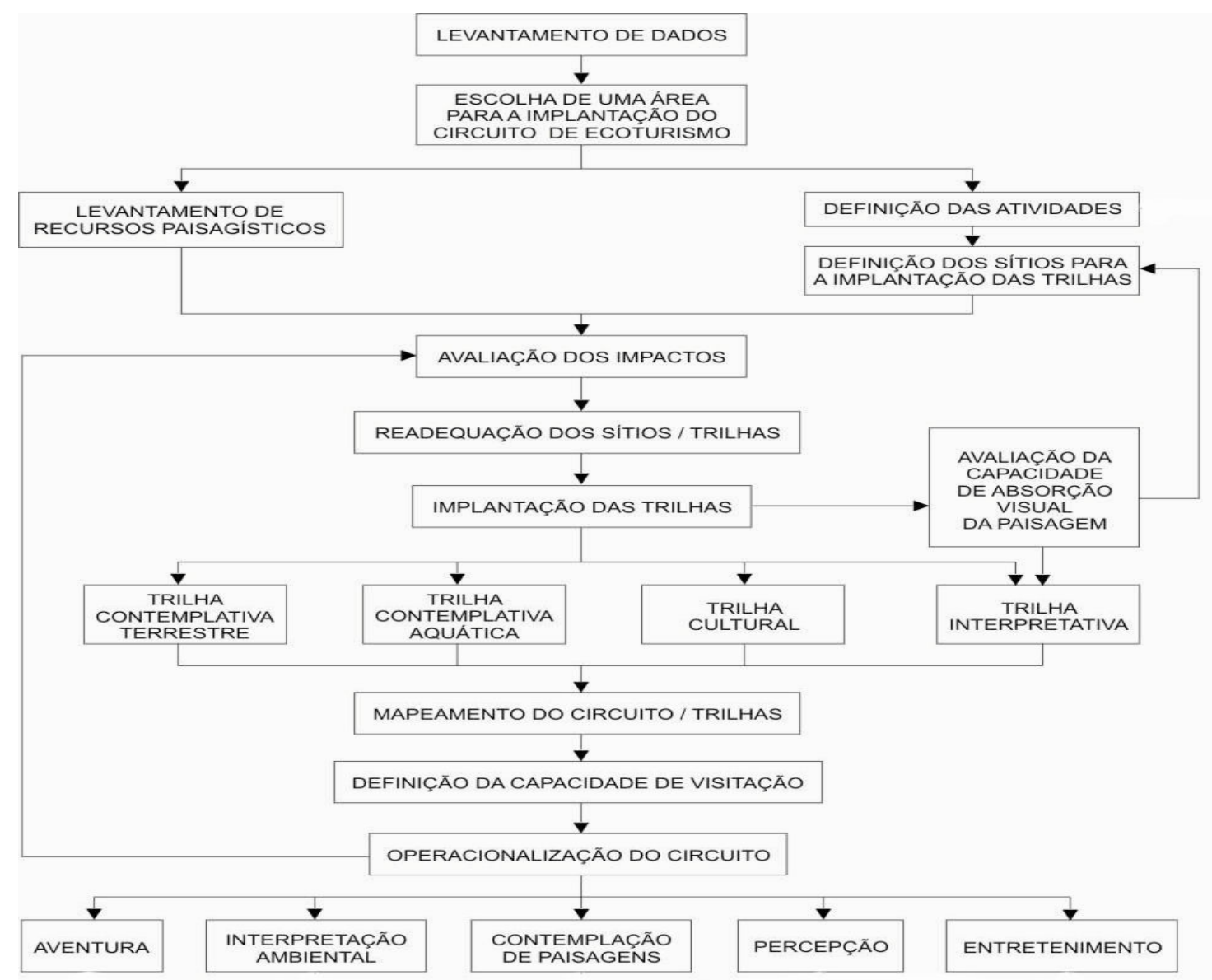

Figura 2 - Fluxograma da metodologia aplicada

c) Levantamento dos recursos paisagísticos: após a escolha da área, procedeu-se o levantamento dos recursos paisagísticos e a avaliação desses quanto à potencialidade para a prática do ecoturismo. Essa ação foi realizada com base em estudos realizados em outras áreas protegidas, citando dentre outros Griffith (1979) e Griffith e Valente (1983). Esses autores consideram o inventário das seqüências paisagísticas e a exploração de diferentes ângulos de visão e observação do contexto cênico das mesmas como um meio de tornar as atividades de contemplação mais atraentes, além do que, enriquecerem a experiência perceptiva das pessoas. 
d) Definição das atividades e sítios naturais para a implantação das trilhas: a etapa seguinte consistiu da definição das atividades a serem realizadas no circuito de ecoturismo a ser implantado e dos sítios para implantação de trilhas. Em conformidade com o rol de atividades programadas, foram definidos quatro sítios para a implantação de trilhas, sendo esses previamente percorridos para avaliação das ações necessárias para a estruturação e operacionalização do circuito.

e) Avaliação dos impactos: constou da avaliação dos possíveis impactos que a implantação do circuito (trilhas) poderia causar aos ambientes e paisagens locais, tanto durante a implantação propriamente dita como na sua operacionalização. Os resultados dessa avaliação e demais critérios de seleção nortearam a definição dos sítios, de forma a viabilizar a prática do ecoturismo na reserva. Para cada trilha fez-se uma análise em particular, definindo-se o melhor percurso a ser feito, sem se perder de vista a riqueza da experiência e das expectativas dos visitantes quanto à observação e ao contato com os recursos paisagísticos da reserva.

f) Readequação dos sítios definidos para a implantação das trilhas: quando necessário dependendo dos resultados da etapa anterior, fez-se a redefinição de trechos originalmente planejados para as trilhas, a partir do momento em que as interferências causadas pela presença das pessoas poderiam gerar danos de maior escala aos componentes físicos e bióticos ao longo do circuito.

g) Avaliação da Capacidade de Absorção Visual das Paisagens: aplicada apenas para o sítio definido para a implantação da trilha de interpretação ambiental, pelo fato de somente nesse sítio ter havido a necessidade de abertura de novo caminho por entre a vegetação florestal, ao contrário das demais, onde foram aproveitados caminhos já existentes. Essa avaliação possibilitou uma averiguação da amplitude de absorção visual que as paisagens encontradas no sítio apresentavam a partir do momento em que a trilha foi aberta. Considerada como o oposto de fragilidade ou vulnerabilidade visual de uma paisagem, a capacidade de absorção visual determina a amplitude de absorção visual de uma paisagem ante as interferências que ocorrem em função de determinada ação, seja essa humana ou natural (Alonso, 1995). Para o autor, quanto maior a fragilidade visual, menor é a capacidade de absorção visual. Assim como a fragilidade, a amplitude pode variar de acordo com a atividade a ser realizada e das características ambientais de um determinado ponto e seu entorno.

h) Implantação das trilhas: a implantação das trilhas levou em consideração os resultados obtidos pelas etapas anteriores, procurando dessa forma fazer o melhor aproveitamento possível da área escolhida para a implantação do circuito de ecoturismo e com o mínimo de 
impactos. Foram definidas três categorias de trilhas, em conformidade com os distintos propósitos de atividades, conforme descrição a seguir.

Trilhas Contemplativas: a proposta de implantação dessas trilhas foi a de promover atividades de recreação e de contemplação dos cenários paisagísticos naturais e antrópicos da reserva. Esses atributos devem também ser associados à aquisição de conhecimentos, nos quais Lima (1998) considera como primordiais para um melhor aproveitamento de atividades em contato com a natureza, como é o caso do ecoturismo. Para deslocamento, optou-se pela utilização de veículos não motorizados, propiciando atividades descontraídas e de baixo impacto. Duas trilhas contemplativas foram planejadas, uma terrestre e outra aquática: a primeira, utilizando-se de uma antiga estrada abandonada que foi adequadamente estruturada para ser percorrida através do uso de carroções. A segunda, projetada para ser percorrida em um trecho de rio utilizando-se canoas (estilo canadense), propiciando, além da contemplação das paisagens e aquisição de conhecimentos dos ambientes, também um pouco de aventura ao longo do circuito.

Trilha Interpretativa: planejada com o intuito de promover uma caminhada por entre a vegetação florestal, e também, a compreensão por parte dos visitantes das características naturais e/ou antrópicas das paisagens encontradas em seu traçado. Para a definição dos temas abordados em pontos de parada nas atividades interpretativas, empregou-se o método IAPI Indicadores de Atratividade em Pontos Interpretativos segundo Magro e Freixêdas (1998). A aplicação do método auxiliou na escolha dos sítios interpretativos da referida trilha, levando-se em consideração que toda a paisagem ao longo de seu percurso apresenta certa uniformidade.

Seguindo os passos propostos pelo método, a definição dos pontos de interpretação exigiu a execução de seis fases distintas de trabalho, sendo essas:

1) Levantamento dos pontos potenciais para a interpretação - consistiu basicamente no inventário dos recursos naturais presentes ao longo da trilha, os quais são interpretados com base em um tema específico. Através desse inventário, foram demarcados (seguindo uma numeração) pontos pré-selecionados para a interpretação;

2) Levantamento e seleção de indicadores - nessa fase, realizou-se um levantamento dos recursos visualmente perceptíveis a partir dos pontos pré-selecionados onde então, foram analisados os indicadores de atratividade desses pontos;

3) Anotação de dados em fichas de campo - para a anotação de dados, elaborou-se uma ficha de campo onde foi anotada a presença ou ausência dos indicadores nos pontos pré- 
selecionados. Cada indicador teve um peso ou valor específico, com base em sua importância para com a qualidade da experiência pelo público trabalhado;

4) Avaliação do potencial interpretativo dos pontos pré-selecionados - a avaliação dos pontos pré-selecionados teve a participação de três técnicos, sendo dois biólogos e um engenheiro florestal. A avaliação foi feita de forma individual, ou seja, cada técnico percorreu a trilha sem a companhia dos demais, fazendo uma avaliação subjetiva de cada ponto e pontuando os mesmos em conformidade com os indicadores de atratividades;

5) Seleção dos pontos interpretativos - foram selecionados aqueles que obtiveram as maiores pontuações nas fichas de campo, considerando a somatória da pontuação dada a cada ponto três técnicos. Antes de serem definitivamente considerados como de interpretação, todos os pontos escolhidos passaram por uma checagem final com a participação dos três técnicos envolvidos na avaliação. Para temas que tiveram somente um ponto pré-selecionado ao longo da trilha, a escolha foi direta, ou seja, sem a necessidade de somatória da pontuação dos três técnicos.

6) Preparação de material descritivo - referente a temas abordados nos pontos de interpretação.

Trilha Cultural: essa trilha que compõe o trecho final do circuito foi alocada sob o leito da estrada que dá acesso à sede administrativa, recepção e hospedagem da Reserva Volta Velha, além de uma Oca Indígena construída para atividades de resgate da cultura indígena brasileira.

i) Mapeamento do Circuito de Ecoturismo: concluída a implantação, realizou-se o mapeamento do percurso de cada trilha individualizada para o conhecimento do tamanho e formato das trilhas com respectivos pontos de parada. Ao final desse procedimento, todos os mapas foram reunidos num só para a representação do circuito de ecoturismo da Reserva Volta Velha.

j) Definição da Capacidade de Visitação: embora a literatura apresente descrições de diferentes métodos para a definição da capacidade de visitação (visitantes/dia), não se fez emprego que nenhum deles no presente trabalho, tendo em vista que persistem dúvidas quanto à precisão dos mesmos. Dessa forma, a definição da capacidade de visitação do circuito de ecoturismo da Reserva Volta Velha foi feita com base na experiência obtida ao longo dos anos com os trabalhos de interpretação e educação ambiental que vêm sendo realizados na área, com o atendimento de públicos diferenciados.

k) Operacionalização do circuito: com a conclusão da fase de planejamento do circuito, teve início a sua operacionalização através do atendimento aos visitantes da reserva. Ao longo do circuito as pessoas têm a oportunidade de participarem de atividades voltadas à interpretação ambiental, contemplação e percepção de paisagens, além do entretenimento, lazer e aventura. 


\section{Resultados e Discussão}

O presente estudo foi realizado durante seis meses, entre julho e dezembro de 2005.

\subsection{Caracterização da área selecionada para a implantação do circuito de ecoturismo}

A área ocupada pelo circuito de ecoturismo da Reserva Volta Velha (considerando de influência direta e indireta) corresponde a aproximadamente 65 hectares ou 5,5\% da extensão da reserva. Nela presenciam-se paisagens bastante heterogêneas, devido à existência de tipologias vegetacionais diferenciadas compostas por florestas primárias e secundárias em diferentes estágios de desenvolvimento, áreas abertas (campos), sistemas aquáticos e habitações humanas. Os principais critérios de escolha para a implantação do circuito foram a presença da variedade de ambientes e paisagens e a facilidade de acesso e deslocamento. Outro fator que influenciou na escolha foi o fato dessa área já se encontrar em parte alterada pela ação antrópica. De acordo com relatos de moradores mais antigos, em determinados pontos ao longo do circuito ocorreram alterações á aproximadamente quarenta anos atrás, tanto pela exploração da vegetação por corte raso como por extração seletiva de madeira. Dessa forma, com a implantação do circuito nessa área, evitou-se a perturbação de locais no interior da reserva recobertos por florestas mais conservadas em seu estado original, mantendo-se assim a integridade ambiental e a conseqüente minimização de impactos sobre espécies animais que habitam esses ambientes.

\subsection{Composição do circuito de ecoturismo}

O circuito de ecoturismo da Reserva Volta Velha (Figura 3) compõe-se de um centro de recepção de visitantes, duas trilhas contemplativas (uma terrestre e outra aquática), uma trilha interpretativa (terrestre), uma trilha cultural (terrestre) e uma oca indígena. Todas as trilhas receberam denominações de acordo com aspectos naturais e antrópicos que se destacam ao longo dos percursos.

A distância percorrida em todo o circuito é em torno de 9.800 metros, sendo gasto para o deslocamento e realização de todas as atividades em média 4 horas. De acordo com o planejado, o circuito oportuniza aos visitantes a participarem de atividades distintas, com a finalidade de promover o contato direto e a interação com os diferentes ambientes e paisagens presentes na reserva. Em cada uma das trilhas, o público tem a oportunidade de aprender sobre os componentes bióticos e abióticos da reserva, assim como, de se deslocarem a locais contendo sítios arqueológicos de povos primitivos da região e vestígios de moradas dos primeiros colonizadores da atual área da reserva. Devido a essas particularidades são 
abordados durante o percurso temas ligados ao contexto natural e antrópico da reserva, tornando as atividades mais interessantes aos visitantes.

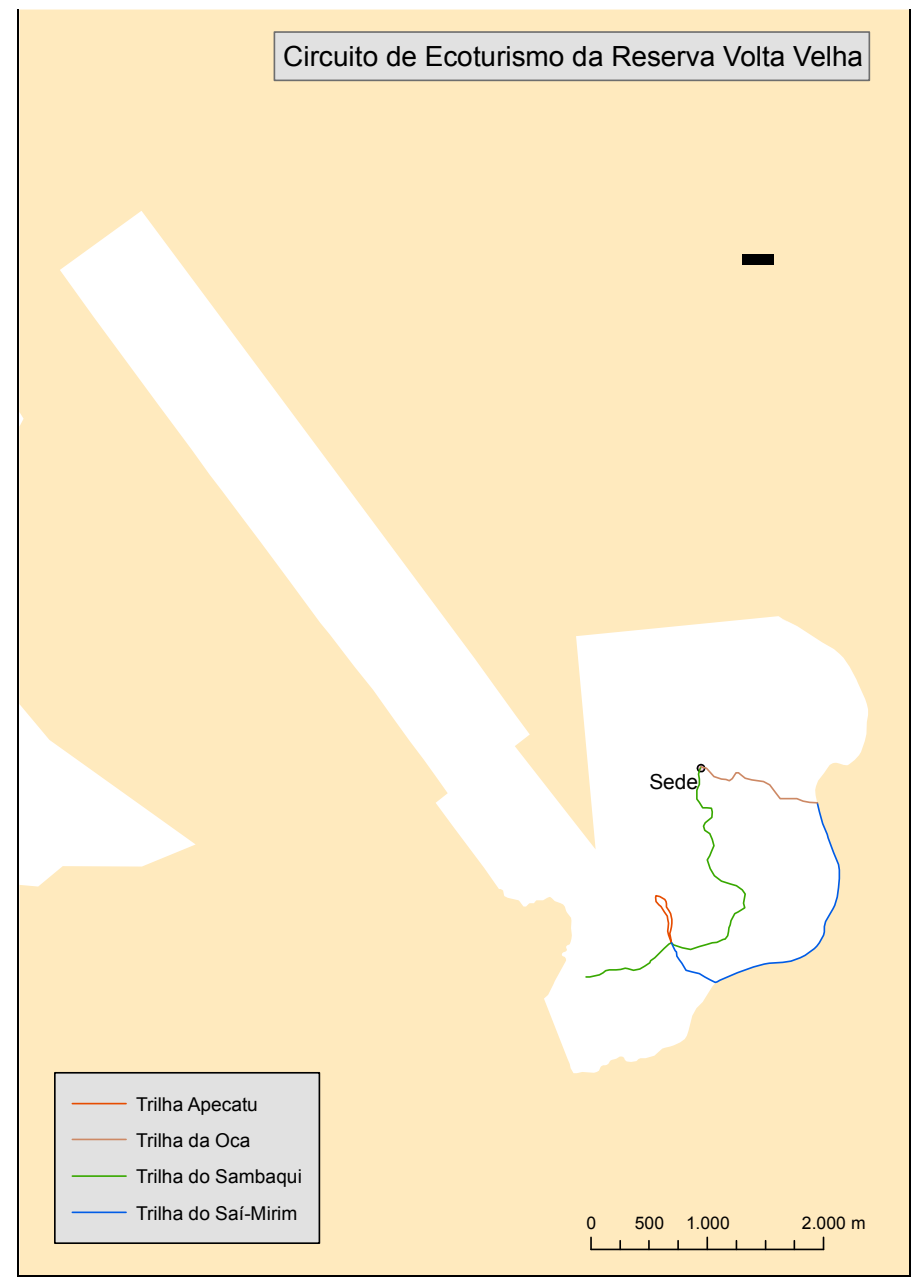

Figura 3 - Formato e localização do circuito de ecuturismo na área da Reserva Volta Velha.

\subsection{Detalhamento do circuito de ecoturismo e das atividades realizadas}

a) Centro de Recepção - Sede: o Centro de Recepção de Visitantes junto à sede da reserva compõe-se do espaço onde se realiza a primeira atividade do circuito de ecoturismo da Reserva Volta Velha. Durante a recepção, os participantes recebem informações gerais sobre normas de visitação à reserva e os procedimentos necessários para uma adequada conduta nas demais atividades.

b) Trilha do Sambaqui: compõe a primeira trilha a ser percorrida no circuito, com início junto ao centro de recepção de visitantes e seu final ao lado de um sambaqui localizado no interior 
da floresta. A distância dessa trilha é de 4.080 metros e as atividades são voltadas à contemplação dos cenários paisagísticos ao longo de seu percurso, ao entretenimento e resgate histórico-cultural dos povos que viveram na área da reserva em tempos remotos.

Ao longo do percurso, paisagens distintas são observáveis, em conformidade com as características dos diferentes locais que atravessa e que são apresentados a seguir:

Área de campo - representada por gramados que se estendem pelo entorno do centro de recepção e sede da reserva;

Área com monocultura - destinada ao plantio de palmeira (Archantophenix sp);

Áreas com vegetação florestal - apresentando formações de Floresta Ombrófila Densa de Terras Baixas em diferentes estágios de crescimento;

Brejos - locais com concentração de água e vegetação típica de solo hidromórfico.

Devido à distância a ser percorrida, é empregado para deslocamento veículo de tração animal (carroção puxado a cavalo), com capacidade de transporte de até 14 pessoas adultas. Para o programa de ecoturismo da Reserva Volta Velha esse veículo foi considerado o mais adequado para o transporte dos visitantes devido a impactos menos significativos que provocam quando comparado a veículos motorizados. Além disso, possibilita uma boa visão de ambientes e paisagens ao longo do percurso da trilha. Para a maioria dos visitantes representa um momento especial por se constituir na primeira viagem feita com esse tipo de veículo. Em três pontos da trilha foram colocadas placas referentes a temas ligados à reserva. A primeira faz abordagem à Floresta Atlântica; sua biodiversidade, seu atual estado de conservação e importância para a preservação da biodiversidade, além das pressões que vem sofrendo pela ação antrópica. A segunda enfoca a presença de Puma concolor (puma), espécie de fauna ameaçada de extinção e de ocorrência na reserva, e, a terceira, o Sambaqui, com assuntos ligados à vida e cultura dos primitivos indígenas que viveram na região.

c) Trilha Interpretativa Apecatu: a trilha Apecatu (do guarani = bom caminho) encontra-se em terreno plano e seco (tabuleiro) e é percorrida a pé. Seu traçado sinuoso apresenta uma distância de 1.450 metros, com a caminhada levando aproximadamente 45 minutos para ser realizada.

Diferentemente das demais trilhas que compõem o circuito de ecoturismo da Reserva Volta Velha, que são de formato linear (iniciam e terminam em pontos diferentes), a Trilha Apecatu tem o formato de uma alça, com o início e final no mesmo ponto. Quanto ao grau de 
dificuldade, pode ser classificada como de grau leve, ou seja, com a caminhada praticamente não exigindo um esforço mais acentuado.

A Trilha Interpretativa Apecatu apresenta uma estrutura que permite seu uso com a geração mínima de impactos sobre os componentes paisagísticos ao longo de seu percurso, além de proporcionar satisfação por parte do visitante devido aos conhecimentos que adquire sobre os ambientes locais ao percorrê-la. Durante a caminhada, é feita uma interpretação interativa com o público, buscando além da participação do mesmo, também averiguar o grau de conhecimento das pessoas em relação a cada tema interpretado. São realizadas 10 paradas para a abordagem de diferentes temas, os quais foram selecionados entre 24 pontos préselecionados, utilizando-se para essa escolha o método IAPI (Magro e Freixêdas, 1998), conforme resultados apresentados na Tabela 1. Além da vegetação e elementos do meio físico, não raro os visitantes têm a oportunidade de observar durante o percurso dessa trilha grupos de Cebus apella (macaco-prego) deslocando-se por entre as copas das árvores e, com menos freqüência, bandos de Nasua nasua (quati).

d) Trilha Contemplativa do Saí-Mirim: a terceira trilha na seqüência de atividades denominada de Trilha Contemplativa do Saí-Mirim (em guarani = boca pequena) é feita por deslocamento em um trecho de aproximadamente 2.850 metros do leito do Rio Saí-Mirim e mais 300 metros de um afluente de nome rio Braço-do-Norte, totalizando 3.150 metros de percurso. Embora o termo "trilha" aqui empregado pareça a princípio estranho pelo fato de se tratar de um rio, o uso do mesmo foi em conseqüência da padronização de nomenclatura com os demais trechos do circuito. Durante o deslocamento dessa trilha, o visitante tem a oportunidade de apreciar belas paisagens formadas pela interação da água com as formações de floresta ripária e, em alguns pontos, as montanhas ao fundo. Para percorrê-la, utilizam-se canoas de fibra estilo canadense, proporcionando uma atividade recreativa e contemplativa associada à baixa produção de impactos nos ecossistemas presentes. Embora Fennel (2002) considere a canoagem como uma atividade ligada mais ao turismo de aventura do que ao ecoturismo, no circuito de ecoturismo da Reserva Volta Velha a mesma foi planejada para ser, além de uma experiência agradável e que exige certo esforço físico, também numa atividade geradora de conhecimentos através de interpretação ambiental em todo o percurso. Com isso foi possível aliar uma atividade de aventura com um contexto educativo, cujo resultado contribui para a formação de uma consciência ambiental, como tem sido destacado por Wearing e Neil (2001) e WWF-Brasil (2001). 
e) Trilha da Oca: última trilha que compõe o circuito de ecoturismo da Reserva Volta Velha, essa trilha, com 1.160 metros de distância, inicia-se ao final da trilha do Saí-Mirim e finaliza na oca indígena. Também nessa trilha faz-se o emprego de um carroção para deslocamento dos visitantes entre o rio Saí-Mirim e a Oca. No interior da Oca as pessoas recebem informações gerais sobre a construção da mesma, além da cultura indígena brasileira. Esse espaço também é utilizado nas atividades de educação ambiental e demais cursos realizados na área da Reserva Volta Velha.

Tabela 1 - Resultados da escolha dos pontos de interpretação da Trilha Apecatu

\begin{tabular}{|c|c|c|c|c|c|c|}
\hline Ponto & Tema & $\begin{array}{c}\text { Pontuação } \\
\text { avaliador 01 }\end{array}$ & \begin{tabular}{|c|} 
Pontuação \\
avaliador 02 \\
\end{tabular} & $\begin{array}{c}\text { Pontuação } \\
\text { avaliador 03 }\end{array}$ & $\begin{array}{c}\text { Total de } \\
\text { pontos }\end{array}$ & \begin{tabular}{|c|} 
Ponto \\
selecionado
\end{tabular} \\
\hline 01 & Floresta secundária & 14 & 12 & 15 & 41 & Sim \\
\hline 02 & Epífitas e lianas & 19 & 23 & 21 & 63 & Não \\
\hline 03 & Epífitas e lianas & 29 & 30 & 34 & 93 & Sim \\
\hline 04 & Cupiuva & 15 & 14 & 14 & 43 & Sim \\
\hline 05 & Floresta secundária & 12 & 11 & 10 & 33 & Não \\
\hline 06 & $\begin{array}{l}\text { Espécie vegetal Ameaçada } \\
\text { (palmito) }\end{array}$ & 08 & 08 & 08 & 24 & Não \\
\hline 07 & Sistema radicular (raízes) & 08 & 06 & 06 & 20 & Sim \\
\hline 08 & Cupiuva & 13 & 15 & 13 & 41 & Não \\
\hline 09 & Epífitas e lianas & 23 & 23 & 24 & 70 & Não \\
\hline 10 & Epífitas e lianas & 19 & 19 & 18 & 56 & Não \\
\hline 11 & Floresta primária & 17 & 17 & 19 & 53 & Sim \\
\hline 12 & Maçaranduba & 09 & 09 & 09 & 27 & Não \\
\hline 13 & Maçaranduba & 07 & 07 & 07 & 21 & Não \\
\hline 14 & Floresta primária & 16 & 17 & 16 & 49 & Não \\
\hline 15 & Maçaranduba & 11 & 14 & 16 & 41 & Sim \\
\hline 16 & Figueira & 13 & 13 & 13 & 39 & Não \\
\hline 17 & Epífitas e lianas & 26 & 26 & 27 & 79 & Não \\
\hline 18 & Ciclo de nutrientes & 12 & 11 & 11 & 34 & Sim \\
\hline 19 & $\begin{array}{l}\text { Espécie vegetal ameaçada } \\
\text { (palmito) }\end{array}$ & 12 & 12 & 13 & 37 & Sim \\
\hline 20 & Epífitas e lianas & 23 & 24 & 24 & 71 & Não \\
\hline 21 & Figueira & 14 & 14 & 14 & 42 & Sim \\
\hline 22 & $\begin{array}{l}\text { Espécie vegetal ameaçada } \\
\text { (palmito) }\end{array}$ & 08 & 08 & 09 & 25 & Não \\
\hline 23 & Ciclo de nutrientes & 11 & 09 & 09 & 29 & Não \\
\hline 24 & Solo & 11 & 11 & 06 & 28 & Sim \\
\hline
\end{tabular}

\subsection{Seqüência das atividades do circuito}

O ecoturismo, segundo Pires (1993), deve ser desenvolvido através de roteiros planejados e com alguma atividade de cunho físico relacionada. Deve despertar nas pessoas o interesse em aprender sobre o espaço que estão visitando. Para tanto, é recomendado que as áreas 
utilizadas para a prática desse segmento turístico possuam de preferência, valores ecológicos e culturais notáveis a fim de dar sentido ao roteiro estabelecido.

Para o circuito de ecoturismo da reserva Volta Velha, a seqüência de atividades foi estrategicamente planejada, buscando com isso manter o ânimo dos visitantes durante todo o percurso. Atividades que exigem maior concentração, como é caso das realizadas na trilha de interpretação ambiental (Trilha Apecatu) são desenvolvidas somente após o percurso da primeira trilha (contemplativa). Nesse momento, os visitantes já se encontram mais integrados ao ambiente e familiarizados com o condutor, possibilitando assim uma caminhada tranqüila e mais proveitosa para a aquisição de conhecimentos. Já as atividades que exigem esforço físico o caso da canoagem realizada na trilha do Saí-Mirim, foram alocadas para serem realizadas mais no final do circuito, sendo que o gasto de energia para remar é compensado pelo visual de grande beleza que o rio oferece. Para completar, a visita à oca (última atividade), apesar de em muitos casos o cansaço se mostrar evidente na feição dos participantes, a curiosidade de adentrar em uma habitação totalmente distinta daquelas encontradas nas cidades, faz com que as pessoas superem a fadiga para conhecer a oca e participar com entusiasmo da atividade.

Todas as atividades realizadas ao longo do circuito de ecoturismo da Reserva Volta Velha são monitoradas, ou seja, têm o acompanhamento de um condutor responsável para o repasse de informações e interpretação dos temas abordados. Pelo fato da reserva ser um centro de resgate da cultura indígena brasileira, esse acompanhamento é realizado por um membro da aldeia Waura, do Parque Indígena do Xingu no Mato Grosso. Pretende-se com o passar do tempo envolver também condutores das comunidades locais.

\subsection{Avaliação e minimização de impactos}

De acordo com Fennel (2002), assim como qualquer ação antrópica a atividade turística em seus diferentes segmentos também é geradora de impactos sobre o componente ecológico e social. Portanto, a ocorrência de impactos ao meio natural com a implantação do circuito de ecoturismo na Reserva Volta Velha deve ser vista como algo inevitável, mas, de certa forma, mitigável pela avaliação realizada sobre os efeitos dos mesmos conforme apresentação a seguir.

a) Vegetação: segundo Horowitz (2001), a vegetação é um dos componentes que sofre os maiores impactos na implantação de trilhas utilizadas para o ecoturismo ou outra atividade. Para minimizar os impactos sobre a vegetação no circuito de ecoturismo da Reserva Volta Velha, fez-se o máximo aproveitamento de trilhas já existentes e que cortavam as florestas, algumas constituídas de antigos leitos de estradas atualmente em desuso. Além dessas, a utilização de 
um trecho do rio Saí-Mirim contribui para a não supressão de vegetação, o que representou uma sensível redução dos efeitos negativos sobre esse componente em todo o percurso do circuito.

Em apenas uma das trilhas (Trilha Interrpetativa Apecatu) houve a necessidade de abertura de novos trechos para adequá-la à atividade ecoturística. Tal ação representou a retirada da vegetação rasteira (bromélias terrestres e plântulas) e, em algumas situações (quando não houve alternativa), também de árvores de pequeno porte. Mesmo que nesse caso tenha havido impactos mais significativos, por outro lado, houve a compensação dos mesmos, com a eliminação de trechos em terreno úmido onde a passagem constante das pessoas provocava a formação de lamaçais, e, com o desvio, o pisoteio da vegetação marginal e conseqüente alargamento da trilha. Para prevenir impactos à vegetação nesses locais, intervenções foram realizadas, permitindo assim no atual percurso da trilha um deslocamento confortável e com impacto praticamente nulo às plantas às margens da mesma.

b) Solo: de acordo com Binelli et al. (1997) terrenos de relevos abaixo de $10 \%$ de declividade apresentam baixo risco de erosão para qualquer tipo de atividade turística. Dessa forma, o fato do relevo de toda a área da reserva Volta Velha ser praticamente plano (com declividade abaixo de 10\%), o risco de impactos (erosão) para todo o circuito foi considerado praticamente nulo para esse componente da paisagem.

c) Água: também para a água os impactos são praticamente nulos pelo fato de não serem utilizados veículos motorizados para o deslocamento e que poderiam gerar efeitos negativos pelo derramamento de combustíveis e lubrificantes. Para evitar que os turistas adentrassem a água e também, houvesse a formação de processos erosivos às margens dos rios nos locais de embarque e desembarque das canoas, foram construídos atracadouros de madeira para assim minimizar os impactos ao meio aquático.

d) Fauna: esse elemento da paisagem é o que a princípio deverá sofrer mais com os impactos negativos provocados pela implantação do circuito, sem, no entanto, com um prognóstico da magnitude desses impactos. De acordo com Salvati (2006), para se avaliar com mais precisão a intensidade dos impactos na fauna é necessário se conhecer bem o comportamento das espécies, o que pode levar vários anos de estudos. Para minimizar os impactos sobre a fauna em toda a extensão do circuito, algumas alterações tiveram que ser realizadas, principalmente em relação à trilha do Saí-Mirim. Por apresentar sítios que se constituem de criadouros para algumas espécies animais, como o caso de Lontra longicaudis (lontra) (Quadros, 1998) essa trilha sofreu modificações em seu traçado original, para que a referida espécie não apresentasse alterações de comportamento e abandono da área. Embora tenha havido uma 
perda para com a contemplação da paisagem, preferiu-se, nesse caso, priorizar a manutenção da integridade ambiental e dos sítios reprodutivos da espécie.

e) Sambaqui: a visitação ao sambaqui tem provocado impactos a esse sítio através do pisoteio e compactação das conchas. Para minimizar os efeitos negativos provocados pelo acesso das pessoas ao mesmo, está previsto a construção de uma pequena plataforma de madeira para que os visitantes possam visualizar o sambaqui a curta distância, sem a necessidade de subir nesse sítio arqueológico.

Além de ações diretas aplicadas para a minimização dos impactos sobre os elementos da paisagem ao longo do circuito, também a decisão de tornar todas as atividades monitoradas e o atendimento de grupos pequenos de turistas por período contribui para a pouca magnitude dos impactos às paisagens da Reserva Volta Velha.

\subsection{Avaliação da capacidade de visitação}

Segundo Takahashi (1997), na maioria das vezes a origem dos problemas provocados aos ambientes naturais pelo uso público não é exatamente um reflexo da quantidade de visitantes, mas sim, da forma como se comportam. Há casos em que um número pequeno de pessoas pode provocar tanto ou até mais danos do que um número grande, o que significa que a definição da capacidade de visitação de uma área por unidade de tempo é algo relativo e depende muito do comportamento e da consciência dos integrantes.

Para o circuito de ecoturismo da Reserva Volta Velha - Itapoá-SC, o número de pessoas sugerido por grupos foi de 14 pessoas por período (manhã e tarde). A definição dessa quantidade foi com base na experiência adquirida ao longo dos anos com os trabalhos de interpretação ambiental que são desenvolvidos na reserva. Além disso, o fato de uma das atividades do circuito ser realizada com o emprego de canoas, onde, uma quantidade maior de pessoas por grupo poderia gerar a dispersão com conseqüente dificuldade de monitoramento e condução do mesmo.

\section{Conclusões}

O procedimento metodológico empregado com base na análise da paisagem para o planejamento do circuito de ecoturismo da Reserva Volta Velha se mostrou bastante eficiente para se atingir os objetivos do trabalho. 
Um dos fatores que contribuiu muito para o êxito do trabalho foi o conhecimento do local juntamente com as informações obtidas de pesquisas científicas realizadas na área a respeito da flora, a fauna, solos e geologia da reserva.

Com o planejamento das atividades, a Reserva Volta Velha que apresenta uma diversidade de ambientes e paisagens, demonstrou ser uma área de grande potencial para a implantação de um circuito de ecoturismo, para o desenvolvimento de atividades de cunho interpretativo, contemplativo e perceptivo.

Devido à valorização dos recursos naturais, especialmente a paisagem, o circuito de ecoturismo da Reserva Volta Velha poderá servir como um modelo de replicação para outras áreas particulares de interesse para a conservação (respeitando-se as particularidades de cada área) sejam essas RPPNs ou outras unidades de conservação que tenham acesso ao público.

Com uma divulgação mais consistente, o circuito de ecoturismo da Reserva Volta Velha poderá se transformar numa das principais alternativas de atividade turística ligada à natureza do Município de Itapoá, estimulando a criação de novas áreas com este uso no estado de Santa Catarina.

\section{Referências}

ALONSO, M. A. 1995. Estudio de Paisagem. Guia para Elaboracion de Estúdios del Médio Físico. Serie Monografia. Ministério de Obras Públicas Transportes y Médio Ambiente. Valencia: Editora Sucessores de Rivadeneyra S.A.. 480-546 pp.

BINELli, A. A.; PINHO, A. M. de e MAGRO, T. C. 1997. Adaptação do método de Miguel Cifuentes para a determinação da capacidade de carga em trilhas do município de Brotas-SP. Curitiba, Congresso Brasileiro de Unidades de Conservação, Anais Vol.II, 358-369 pp.

BOLSON, J. H. G. A Importância da Paisagem na Atividade Turística. Disponível em: $<$ http://revistaturismo.cidadeinternet.com.br/artigos/paisagem.html $>$. Acesso: 27/08/2004.

BOULLÓN, R. C. 2002. Planejamento do Espaço Turístico. Bauru-SP: EDUSP, 278p.

COSTA, P. C. 2002. Unidades de Conservação - Matéria Prima do Ecoturismo. São Paulo: Aleph (série turismo), 163p.

EMBRATUR. Ecoturismo no Brasil. Disponível em: <http://embratur.gov.br>. Acesso: 10/02/2005.

FENNEL, D. A. 2002. Ecoturismo. Uma introdução. São Paulo: Contexto, 282p.

GRIFFTH, J.J. 1979. Análise dos Recursos Visuais do Parque Nacional da Serra da Canastra. Brasil Florestal, 09(40), 13-21 pp.

GRIFFTH, J.J.; VALENTE, O. F. 1983. Aplicação da Técnica de Estudos Visuais no Planejamento da Paisagem Brasileira. Brasil Florestal 10(37), pg. 06-13.

HOROWITZ, C. 2001. Trilha da Capivara. Parque Nacional de Brasília. Brasília: Ed. IBAMA, 64p. 
IBGE - INSTITUTO BRASILEIRO DE GEOGRAFIA E ESTATÍSTICA. 1992. Manual Técnico da Vegetação Brasileira. Fundação Instituto Brasileiro de Geografia e Estatística. Departamento de Recursos Naturais e Estudos Ambientais. Rio de Janeiro, Série Manuais Técnicos em Geociências, n. ${ }^{\circ}$ 1. 92p.

LIMA, S. T. 1998. Trilhas interpretativas: a aventura de conhecer a paisagem. Paisagem. Paisagens 3, Rio Claro, 39-43 pp.

MAGRO, T. C. e FREIXÊDAS, V. M. 1998. Trilhas: como facilitar a seleção de pontos interpretativos. Instituto de Pesquisas e Estudos Florestais - SP, Circular Técnica n. ${ }^{\circ} 186$, setembro. $8 \mathrm{p}$.

MILANO, M. S. 1993. Unidades de Conservação - Conceitos Básicos e Princípios Gerais de Planejamento, Manejo e Administração. Curso sobre Manejo de Áreas Protegidas. Universidade Livre do Meio Ambiente, Curitiba-PR, 01-63pp. (apostila).

MMA - MINISTÉRIO DO MEIO AMBIENTE. 2004. Sistema Nacional de Unidades de Conservação - SNUC. Lei n. ${ }^{0}$ 9.985, de 18 de julho de 2000; decreto n. ${ }^{\circ} 4.340$, de 22 de agosto de 2002. $5^{\mathrm{a}}$ ed. Aum. Brasília: MMA/SBF, 56p.

NEGRELLE, R. R. B. 1995. Composição Florística, Estrutura Fitossociológica e Dinâmica de Regeneração da Floresta Atlântica na Reserva Volta Velha, Mun. Itapoá-SC. São Carlos-SP. Tese de Doutorado - Programa de Pós-Graduação em Ecologia e Recursos Naturais do Centro de Ciências Biológicas e da Saúde da Universidade de São Carlos. 218p.

PIRES, P. S. 1993. Turismo em Áreas Naturais Protegidas. Curso sobre Manejo de Áreas Protegidas. Universidade Livre do Meio Ambiente, Curitiba-PR, 63-75pp. (apostila).

QUADROS, J. 1998. Aspectos da Ecologia de Lontra Longicaudis (Olfers, 1818) em uma Área de Floresta Atlântica de Planície, Município de Itapoá-SC. Curitiba, Dissertação (Mestrado em Zoologia), Pós-Graduação em Ciências Biológicas, Universidade federal do Paraná. 71p.

SALVATI, S. S. Impactos Ambientais em Trilhas. Disponível em: $<$ http://ecosfera.sites.uol.com.br/int_amb.htm>. Acesso: 10 de fevereiro de 2006.

TAKAHASHI, L. Y. 1997. Limite Aceitável de Câmbio (LAC): Manejando e Monitorando Visitantes. Curitiba, Congresso Brasileiro de Unidades de Conservação, Anais Vol. 01.

WEARING, S. e NEIL, J. 2001. Ecoturismo - Impactos, Potencialidades e Possibilidades. São Paulo. Ed. Manole, 256p.

WWF-BRASIL. 2001. Uso Recreativo do Parque Nacional Marinho de Fernando de Noronha: um exemplo de planejamento e implementação. Série Técnica, Volume VIII, Fev.

\section{Recebido em: 24/05/2007 (1 ${ }^{\mathrm{a}}$ versão) 11/04/2008 ( $2^{\mathrm{a}}$ versão)}

Aprovado em: 30/05/2008 